\title{
A DISSOLUÇÃo COMPULSÓRIA DA PESSOA JURÍDICA NA LEI ANTICORRUPÇÃO E O APARENTE CONFLITO COM O PRINCÍPIO DA FUNÇÃO SOCIAL DA EMPRESA E O PRINCÍPIO DA PRESERVAÇÃO DA EMPRESA
}

\author{
Bruno Roberto Vosgerau ${ }^{1}$ \\ Mateus Eduardo Siqueira Nunes Bertoncini²
}

\begin{abstract}
RESUMO: Dentre as novidades da Lei 12.846/2013, também conhecida como Lei Anticorrupção, especial atenção merece a possibilidade da dissolução compulsória da pessoa jurídica, quando esta é autora de atos lesivo à Administração Pública, nacional ou estrangeira, isso porque existe aparente conflito entre essa medida do Direito Administrativo Sancionador e os princípios da função social da empresa e o da preservação da empresa. Após realizada a análise das hipóteses da pesquisa, mediante o emprego do método dedutivo, obteve-se três diferentes conclusões a respeito da compatibilidade da referida sanção e os aludidos princípios que informam a atividade econômica.
\end{abstract}

Palavras-chave: Lei 12.846/2013, Lei Anticorrupção, dissolução compulsória da pessoa jurídica, princípio da função social da empresa, princípio da preservação da empresa.

\section{THE COMPULSORY DISSOLUTION OF THE LEGAL ENTITY IN THE}

ANTICORRUPTION LAW AND THE APPARENT CONFLICT WITH THE PRINCIPLE OF THE COMPANY'S SOCIAL FUNCTION AND THE PRINCIPLE OF THE PRESERVATION OF THE COMPANY

\begin{abstract}
Among the novelties of Law 12.846/2013, also known as Anti-Corruption Law, special attention deserves the possibility of compulsory dissolution of the legal entity, when it is the author of acts prejudicial to the Public Administration, national or foreign, because there is an apparent conflict between this sanction and the principles of the social function of the company and of the preservation of the company. After analyzing the hypothesis of the research, using the deductive method, three different conclusions were obtained regarding the compatibility of said sanction and the aforementioned principles that inform the economic activity.
\end{abstract}

Keywords: Law 12.846/2013, Anti-Corruption Law, compulsory dissolution of the legal entity, principle of the company's social function, principle of company preservation.

\footnotetext{
${ }^{1}$ Mestrando em Direito Empresarial e Cidadania - Centro Universitário Curitiba - UNICURITIBA. Pós-graduado em Direito e Processo do Trabalho pela Pontifícia Universidade Católica do Paraná (PUC-PR). Pós-graduado em Direito Público pela ESMAFE-PR/UniCESUMAR. E-mail: bruno@vec.adv.br

${ }^{2}$ Pós-Doutor em Direito pela UFSC, Doutor e Mestre em Direito do Estado pela UFPR. Professor Titular de Direito Administrativo da Faculdade de Direito de Curitiba. Membro do Corpo Docente Permanente do Programa de Mestrado em Direito Empresarial e Cidadania do Centro Universitário Curitiba (UNICURITIBA). Procurador de Justiça do Ministério Público do Estado do Paraná. E-mail: mateusbertoncini@uol.com.br
} 


\section{INTRODUÇÃO}

A corrupção no Brasil não é novidade, é talvez uma das maiores mazelas enfrentadas pelo país com capacidade de atrapalhar o bem-estar de toda a população, pois o seu custo é extremamente gravoso, uma vez que retira recursos de áreas como saúde, educação e segurança para o financiamento de "projetos" ilícitos de quem participa desses esquemas.

Os atores envolvidos em grandes casos de corrupção normalmente são agentes políticos e empresas de porte, muito em virtude do que podem fornecer uns para os outros, a exemplo dos pagamentos de propinas pelas pessoas jurídicas em troca de facilidades para vencer licitações, as quais são fraudadas pelos agentes públicos garantindo-se contratações superfaturadas. Nessas situações, ambos os lados saem ganhando em detrimento do erário e da população, pois nos contratos superfaturados parte dos valores pagos é repassado aos agentes, que por sua vez direcionam as licitações às empresas, que obtém lucros com as negociatas.

Diante desta problemática, somada à necessidade de o Brasil dar cumprimento a compromissos internacionais assumidos no combate à corrupção, foi editada a Lei Anticorrupção (Lei 12.846/2013), diploma que integra o Direito Administrativo brasileiro, aplicável às pessoas jurídicas que cometam atos lesivos contra a Administração Pública, nacional ou estrangeira.

Além de prever a responsabilidade objetiva da pessoa jurídica, a Lei, dentre as sanções aplicáveis, previu a possibilidade de dissolução compulsória empresa, caso atendidas qualquer uma das seguintes hipóteses: (i) ter sido a personalidade jurídica utilizada de forma habitual para facilitar ou promover a prática de atos ilícitos, ou (ii) ter sido constituída para ocultar ou dissimular interesses ilícitos ou a identidade dos beneficiários dos atos praticados.

Porém, com esta sanção, também se criou um possível conflito entre essa dissolução e os princípios da preservação e da função social da empresa. A Constituição da República reconhece a função social da empresa, de modo que a sua preservação é um subprincípio decorrente do princípio inscrito no art. 170, inciso III, da Lei Maior. Logo, surge o seguinte questionamento: como o Estado, ao mesmo tempo em que deve incentivar e preservar as empresas, edita uma Lei que prevê, dentre as suas sanções, a dissolução da pessoa jurídica?

Para verificar o eventual conflito, o presente trabalho analisou três hipóteses distintas para que ao final fossem produzidos os subsídios necessários para uma possível resposta à relevante problemática: (i) a pessoa jurídica constituída para ocultar ou dissimular interesses 
ilícitos ou a identidade dos beneficiários dos atos praticados (inciso II do $\S 1^{\circ}$ do art. 19); (ii) a pessoa jurídica que tem sua personalidade jurídica habitualmente empregada para facilitar ou promover a prática de atos ilícitos (inciso I do $\S 1^{\circ}$ do art. 19); e, por fim, (iii) a pessoa jurídica utilizada para a prática de atos ilícitos.

A importância do tema é inequívoca, posto que numa ordem econômica capitalista como a adotada pela Constituição de 1988, a empresa privada desempenha relevante função social não apenas produzindo bens e serviços consumidos pela comudidade, mas também gerando empregos e tributos, essenciais à população e ao financiamento do Estado, responsável pela prestação de serviços públicos.

A partir de pesquisa bibliográfica e da utilização do método dedutivo, foram envidados os esforços necessários ao enfrentamento da problemática trazida pela pesquisa, cujos resultados, ao final, parecem expressar de forma adequada a aplicação da sanção de dissolução da empresa - categoria do Direito Administrativo Sancionador, com previsão na Lei Anticorrupção - e os princípios da função social e da preservação da pessoa jurídica, sem prejuízo do enfrentamento da corrupção - ainda endêmica - existente no Brasil.

\section{PRINCÍPIO DA FUNÇÃO SOCIAL DA EMPRESA}

Com a evolução das atividades empresariais, e com a necessidade de o Estado regulamentá-las, o direito empresarial adquiriu autonomia em face dos demais ramos. O objetivo era conceder às relações comerciais maior segurança jurídica por intermédio da previsibilidade, e assim, através da legislação, pretendeu-se impulsionar o desenvolvimento econômico com a preservação de interesses de cada nação.

No ordenamento jurídico brasileiro, a atividade empresarial deve ser pautada pela observância ao princípio da função social, que decorre da interpretação do inciso XXIII do art. $5^{\circ}$, em que prevê que "a propriedade atenderá a sua função social" e do inciso III do art. 170 da Constituição da República, que dispõe que a ordem econômica, "fundada na valorização do trabalho humano e da livre iniciativa, tem por fim assegurar a todos uma existência digna, conforme os ditames da justiça social, observados os seguintes princípios: III- função social da propriedade"; porém, da leitura do texto normativo, não é possível extrair o que seria a empresa cumprir com sua função social. 
No Código Civil de 2002, pela interpretação dada ao $§ 1^{\circ}$ do art. 1.228 , em que trata da propriedade, é possível retirar alguns elementos norteadores, ao prever que:

o direito de propriedade deve ser exercido em consonância com suas finalidades econômicas e sociais e de modo que sejam preservados, de conformidade com o estabelecimento em lei especial, a flora a fauna e as belezas naturais, o equilíbrio ecológico e o patrimônio artístico, bem como evitada a poluição do ar e da água.

A empresa, como instituto de direito privado ("atividade econômica organizada para a produção ou circulação de bens e serviços" - art. 966 do Código Civil de 2002), deve respeito, assim como todos os demais entes previstos na lei civil, à uma função social.

Ao se assemelhar com o instituto da propriedade, em decorrência de o empresário possuir o controle de todos os bens da empresa, havendo a possibilidade de sua utilização em outras relações jurídicas, como a venda de sua produção, pode-se extrair que o $\S 1^{\circ}$ do art. 1.228 do Código Civil é também plenamente aplicável à empresa.

Verifica-se que o dispositivo legal enfatiza aspectos ambientais, que por certo são elementos que compõe a função social da empresa, porém, deixa em aberto o que se deve entender por finalidades econômicas e sociais.

Para Adams e Oliveira (2015, p. 101):

\begin{abstract}
A função social da propriedade é correlata à função social do contrato e da empresa. No Código Civil não há explicitamente a função social da empresa, de modo que aplica-se a ela o art. 421 da mesma legislação: sua sociedade significa a democratização e moralização do governo da empresa, e a concretização de uma conduta que atende aos superiores interesses do país e da sociedade.
\end{abstract}

Deste modo, diante da concepção de função social, na legislação, possuir certo grau de indeterminação, coube à doutrina delimitá-la.

Eduardo Tomascevicius Filho (2003, p. 40) define que é o "poder dever de o empresário e os administradores da empresa harmonizarem as atividades [...], segundo o interesse da sociedade, mediante a obediência de determinados deveres positivos e negativos".

Como interesses da sociedade, podemos considerar inúmeras situações, como exemplo a observância da legislação pertinente, o desenvolvimento sustentável de sua atividade, a geração de empregos e a contribuição para o crescimento local.

Nesse sentido, expõe Santiago (2008, p. 113): 
A função social da empresa limita a vontade e o interesse dos detentores do capital, substituindo o poder arbitrário do dono do negócio pelo equilíbrio que deve passar a existir entre as forças que cooperam para o desenvolvimento das finalidades empresariais. Trata-se, assim, como no caso da função social do contrato, de submeter o interesse particular ao interesse social.

Invariavelmente uma empresa é criada para gerar e ter como objetivo principal o lucro, e consequentemente se utiliza da eficiência para maximizá-lo. Assim a função social a ela imposta, na verdade, caracteriza-se como uma limitação determinada pelo Estado à irrestrita liberdade na condução das atividades empresariais.

Desse modo, a função social da empresa tem como objetivo conduzir a atividade desenvolvida a transcender aos interesses meramente individuais, principalmente do empresário e dos controladores que é o lucro, respeitando o que é necessário para que se construa uma sociedade justa e digna, conforme se extrai do caput do art. 170 da Constituição da República.

Até o momento, toda forma de conceituação do que seria a função social da empresa decorreu de uma verificação normativa e da interpretação a ela dada, porém, segundo Ricci (2012):

Falar que a função social da empresa ocorre quando esta obedece às regras ambientais, respeita os direitos trabalhistas e do consumidor, não pratica ato de concorrência desleal, não atribuiu a ela conteúdo jurídico algum, pois sempre se estará a justificar a função social da empresa com base em outras normas.

A afirmativa demonstra-se pertinente, pois não há norma jurídica em sentido estrito que defina quais são as condições necessárias para que a função social da empresa seja cumprida, além disso, há sempre remissão sobre esta circunstância em outras normas, como as ambientais, concorrenciais etc. Novamente, é de se dizer, toda a construção do que seja essa função decorreu da interpretação dada ao texto normativo, mas não de sua literalidade.

Deste modo, diante da vagueza quanto ao conceito de função social da empresa, Ricci (2012) defende que se trataria apenas de um valor a ser perseguido e não uma obrigação gerada a partir da norma.

Ainda que haja este entendimento, o que prevalece é a necessidade de que a empresa observe sua função social, porquanto não se pode cogitar, em um Estado Democrático de Direito, que as atividades empresariais não guardem relação com a sociedade, com os interesses 
difusos e coletivos, com os trabalhadores etc., tal como definido na Constituição de 1988, na parte reservada à atividade econômica.

\title{
2. PRINCÍPIO DA PRESERVAÇÃO DA EMPRESA
}

Outro princípio atrelado à empresa é o da necessidade de sua preservação, o seu fundamento base pode ser retirado do próprio princípio da função social, pois tudo aquilo que produz vantagens para a sociedade e ao Estado de forma adequada e lícita deve ser protegido. Nesse sentido, Ricci (2012) aponta que o direito reconhece a empresa

\begin{abstract}
como bem jurídico na medida em que esta tem uma função social, gerando riquezas, empregos, tributos. A proteção que é dada a empresa demonstra que o legislador pressupõe tal valor (função social da empresa) ao legislar. A atividade empresarial é, inclusive, elemento de pacificação social e de manutenção do Estado, já que garante empregos e abastece o erário.
\end{abstract}

É inegável os benefícios que a atividade empresarial pode gerar para a sociedade, e em virtude disso, o direito buscou mecanismos para protegê-la; o principal deles está materializado no art. 47 da Lei 11.101/2005:

\begin{abstract}
a recuperação judicial tem por objetivo viabilizar a superação da situação de crise econômico-financeira do devedor, a fim de permitir a manutenção da fonte produtora, do emprego dos trabalhadores e dos interesses dos credores, promovendo, assim a preservação da empresa, sua função social e o estímulo à atividade econômica.
\end{abstract}

Preservar a empresa é preservar o interesse social, pois é em virtude de sua atividade que há a produção de riquezas que geram para o Estado receitas derivadas com o pagamento de tributos, além de ser fonte geradora de empregos, fundamental para garantir sustento à diversas famílias.

Nesse sentido, defende Etcheverry (1994, p. 569-670) que a preservação da empresa é um princípio geral de direito de aplicação prática, pois é do interesse coletivo a continuidade de suas atividades, e caso a unidade produtiva seja encerrada, certamente restaria um prejuízo social e econômico.

O valor prestigiado é o da manutenção da atividade transcendendo os interesses meramente individuais do empresário ou da sociedade empresária, isso porque há outros bens jurídicos a serem protegidos como a preservação dos empregos dos trabalhadores, os direitos 
dos credores, a existência de um consumidor de atividade e/ou produtos prestados/produzidos por outras pessoas físicas ou jurídicas, o funcionamento como fonte de recursos do erário, dentre outros.

"A ideia de preservação da empresa envolve a separação entre a sorte da empresa (atividade) e a sorte do seu titular (empresário individual ou sociedade), bem como da sorte dos sócios e dirigentes da sociedade" (TOMAZETTE, 2011, p. 51). Isso significa dizer que a preocupação social de proteção é voltada à atividade e não ao seu titular, é bem verdade que em alguns casos, por via reflexa, o empresário ou a sociedade acabam experimentando as vantagens desta proteção, o que não modifica o objetivo ou valor do princípio em análise.

A preservação da empresa também objetiva a possibilidade de que seja cumprida a sua função social (MAMEDE, 2013, p. 51), além de colaborar com a promoção do desenvolvimento social.

A empresa está enraizada na estrutura social, a sua atuação é capaz de gerar impacto direto na sociedade, principalmente na comunidade em que está localizada. Diante disso, não se pode perder de vista a relevância e o grau de influência deste ente na sociedade, o que justifica a proteção normativa.

Desta forma, não se pode analisar a empresa como apenas um negócio individualizado pertencente a uma pessoa ou a um grupo, mas sim como uma instituição social que deve “ocupar-se das condições de possibilidade da credibilidade social da ação empresária e, portanto, da confiança nela depositada por parte de todos aqueles grupos que formam parte ou estão relacionados por sua atividade" (GARCIA-MARZÁ, 2007, p. 27), para promover benefícios sociais.

Ao final, pode-se concluir que o princípio da preservação da empresa está intimamente ligado ao princípio da função social; logo, busca-se preservar a atividade para que relevantes interesses coletivos sejam mantidos, de modo que auxiliem no desenvolvimento e na edificação de uma sociedade melhor.

Portanto preservar a empresa é em última análise atender aos interesses sociais, porém, com o advento da Lei 12.846/2013, conhecida como Lei Anticorrupção, inseriu-se no ordenamento jurídico a possibilidade de dissolução compulsória da pessoa jurídica envolvida na prática de atos ilícitos, o que aparentemente não se coaduna com os princípios analisados, de modo que à luz de uma verificação superficial, nota-se a existência de colisão entre a extinção da pessoa jurídica e a necessidade de sua preservação e de sua função social. 
Em virtude disso, será realizada uma análise quanto a dissolução da pessoa jurídica à luz dos princípios da função social da empresa e da sua preservação, com o objetivo de verificar se há incompatibilidade de tal hipótese com o ordenamento jurídico ou se podem coexistir em harmonia.

\section{A LEI ANTICORRUPÇÃO BRASILEIRA - LEI 12.846/2013}

A edição da Lei 12.846/2013 decorreu de vários compromissos internacionais assumidos pelo Brasil ao ratificar convenções que estabeleceram regras de repressão à corrupção internacional.

Conforme o brasileiro se acostumou, com relativa frequência os diversos esquemas de corrupção têm sido desvendados e, em grande parte, há a constatação do envolvimento de grandes empresas nacionais, sejam elas exclusivamente privadas, sejam elas estatais.

Não é por outro motivo que a Lei Anticorrupção elegeu um alvo assertivo para incidir: as pessoas jurídicas, principalmente em suas relações com a Administração Pública.

A lei tem como objetivo trazer um novo regramento contra os crimes derivados de corrupção, porém, como em muitos casos ocorre nas definições jurídicas, em virtude de termos vagos ou de muitos significados, o conceito do que deve ser entendido como corrupção não está bem definido, talvez consciente disso, o legislador a tenha utilizado no texto normativo apenas uma vez, mais especificamente no caput do art. $9^{\circ}$, referindo-se à Convenção sobre Combate da Corrupção de Funcionários Públicos Estrangeiros em Transações Comerciais Internacionais.

Porém, não obstante ao fato de a Lei não definir o que é corrupção, certo é que em seu art. $5^{\circ}$ há a definição dos atos a serem sancionados, assim considerados como "típicos, antijurídicos e objetivamente imputáveis à pessoa jurídica, dos quais resultam a aplicação proporcional das sanções previstas respectivamente nos arts. $6^{\circ}$ e 19 da Lei em referência, além do ressarcimento integral dos danos" (SANTOS, BERTONCINI, FILHO, 2015, p. 158).

Da lista de atos contida na Lei, a grande maioria das infrações já possui tipificação na legislação penal, não obstante a isso, “os atos lesivos à administração pública, nacional ou estrangeira, possuem natureza peculiar, inconfundível (...) com as responsabilidades civil, penal, por improbidade administrativa, política e disciplinar" (SANTOS, BERTONCINI, FILHO, 2015, p. 157), nesse sentido, os atos lesivos descritos na Lei em análise "possuem 
natureza jurídica própria e independente, sujeitando-se a um regime jurídico especial" (SANTOS, BERTONCINI, FILHO, 2015, p. 157).

Há que se dizer que é no artigo $1^{\circ}$ da Lei Anticorrupção que há a previsão de quais são os sujeitos que estão sob sua tutela, evidenciando o foco nas pessoas jurídicas pela prática de atos contra a Administração Pública, seja ela nacional ou estrangeira, além disso, a responsabilização passa a ser objetiva, conforme os termos do art. $2^{\circ}$.

Neste ponto, reside as primeiras considerações, nos termos da Lei, os atos previstos em seu art. $5^{\circ}$ conjugados com a existência de interesse ou benefício, exclusivo ou não, já ensejaria a responsabilização objetiva da pessoa jurídica.

Assim, haveria a simples fórmula para verificar a responsabilização: "ato corrupto + benefício/interesse da empresa = sanção", isso porque "a redação sequer exige que o ato haja sido praticado por representante legal, empregado, procurador, ou qualquer pessoa representante da pessoa jurídica, ou que a entidade tenha algum envolvimento ou participação no ato de corrupção", assim, "basta, na literal dicção da lei, que o ato lhe seja benéfico" (FILHO, 2017, p. 61).

Diante disso, poder-se-ia afirmar que a Lei 12.846/2013 adotou uma concepção amplíssima de responsabilidade objetiva, porém, não é o que deve prevalecer.

Nesse sentido, "a interpretação que parece mais consentânea com a ratio legis e com os artigos $1^{\circ}$ e $3^{\circ}$ é a de que o ato corrupto deve ter sido praticado por agente que de algum modo representava o interesse da empresa envolvida na prática corrupta" (FILHO, 2017, p. 62).

Há a necessidade de haver uma relação de conexão entre o agente realizador da conduta e a pessoa jurídica, para se evitar possíveis injustiças e abusos na aplicação desta Lei, não se pode responsabilizar uma empresa pela prática de ato de um terceiro que com ela não possua nenhum tipo de vínculo.

Devido a esta nova interpretação, Filho (2017, p. 63) reapresenta a fórmula de responsabilização para o seguinte modo: "ato corrupto de agente/representante + benefício/interesse da empresa = sanção", de forma mais completa, pode-se afirmar que para a configuração dos atos lesivos à administração pública deve haver:

1. o cometimento de atos de corrupção "lato sensu", tipificados nos incisos do art. $5^{\circ}$; $2 .^{\circ}$ o benefício direto ou potencial da pessoa jurídica em razão da prática do(s) ato(s) lesivo(s) à administração pública, nacional ou estrangeira;

3. ${ }^{\circ}$ o nexo de causalidade entre a prática de alguma ou algumas das infrações definidas na Lei $12.846 / 2013$ e a vantagem ou benefício auferido ou potencialmente desejado 
pela pessoa jurídica, caracterizando a sua responsabilidade objetiva; (SANTOS, BERTONCINI, FILHO, 2015, p. 163).

É importante frisar que "a responsabilização judicial é deflagrada por uma ação cível de responsabilização da pessoa jurídica por ato lesivo à Administração Pública, a qual visa à aplicação isolada ou cumuladamente, das sanções" (QUEIROZ, 2017, p. 586), portanto, as sanções previstas no artigo 19 possuem natureza cível, e estão sujeitas à cláusula de reserva de jurisdição, isto é, somente o Poder Judiciário poderá aplicá-las.

A competência para o processamento e julgamento da ação é da Justiça Comum Estadual, desde que não haja nenhuma das hipóteses constitucionalmente previstas atribuídas à Justiça Federal, a exemplo da competência em razão da pessoa (pessoa jurídica de direito público federal como autarquias, empresa pública e a União).

No caput do art. 19 há a previsão dos legitimados a proporem a ação cível, sendo eles a União, os Estados, os Municípios e o Ministério Público.

Dentre as sanções, chama a atenção para a prevista no seu $\S 1^{\circ}$ em que se define a dissolução compulsória da pessoa jurídica, apesar de somente poder ser declarada através de ação própria, e se preenchidos os requisitos do inciso I e II, verifica-se nesta punição um grau elevado de severidade. Segundo Queiroz (2017, p. 616-617) “um mal necessário, pois somente com essa medida extrema será possível impedir a reiteração da prática de atos ilícitos (prevenção especial) e evitar que outras empresas também pratiquem ilícitos (prevenção)”.

Diante disso, a possibilidade da dissolução da pessoa jurídica deve ser muito bem analisada, pois conforme assevera Santos (2015):

Das sanções previstas na responsabilização judicial da Lei Anticorrupção, a dissolução compulsória da pessoa jurídica é a nosso ver a mais gravosa, todavia, o legislador define de modo bem transparente as condutas e as circunstâncias que se verificadas podem levar a esta penalidade, quais sejam, ter sido a personalidade jurídica utilizada de forma habitual para facilitar ou promover a prática de atos ilícitos, ou, ter sido constituída para ocultar ou dissimular interesses ilícitos ou a identidade dos beneficiários dos atos praticados.

Sobre as duas hipóteses que dão azo à dissolução compulsória, é preciso dizer que a contida no inciso I retrata empresas que habitualmente estão envolvidas na prática de atos ilícitos, que possuem um histórico negativo com a Administração Pública, e como se sabe, no Brasil, há muitas empresas que sobrevivem apenas de contratações com entes públicos, sem diversificar a sua carteira de clientes. A prevista no inciso II retrata o caso de empresas que não 
foram criadas para gerar riquezas, mas sim, para serem utilizadas com o fim precípuo de cometimento de atos ilícitos.

Feitas breves considerações sobre as hipóteses previstas para a extinção da pessoa jurídica, focaremos a verificação na existência de eventual conflito com o princípio da função social e da preservação da empresa.

\section{HIPÓTESES ANALISADAS}

Para a obtenção de possível resposta para a problemática proposta no presente trabalho, elegeu-se três hipóteses para a verificação da existência de eventuais conflitos entre a extinção da pessoa jurídica e o princípio da preservação da empresa e de sua função social.

A primeira hipótese a ser analisa é a relativa à pessoa jurídica constituída para ocultar ou dissimular interesses ilícitos ou a identidade dos beneficiários dos atos praticados (inciso II do $\S 1^{\circ}$ do art. 19); a segunda diz respeito a pessoa jurídica que utiliza habitualmente a sua personalidade jurídica para facilitar ou promover a prática de atos ilícitos (inciso I do $\S 1^{\circ}$ do art. 19); e, por fim, a hipótese da pessoa jurídica que é utilizada para a prática de atos ilícitos.

\subsection{Dissolução da pessoa jurídica constituída para ocultar ou dissimular interesses ilícitos ou a identidade dos beneficiários dos atos praticados}

O inciso II do $\S 1^{\circ}$ do art. 19 da Lei 12.846/2013 determina a dissolução da pessoa jurídica quando comprovado ter sido constituída para ocultar ou dissimular interesses ilícitos ou a identidade dos beneficiários dos atos praticados.

Esta circunstância possui correlação com a infração prevista no inciso III do art. $5^{\circ}$, em que poderá haver a utilização de pessoas físicas para ocultar ou dissimular os reais interesses ilícitos da pessoa jurídica ou a identidade dos beneficiários dos atos ilícitos praticados; nestes casos há a participação dos famosos "laranjas", terceiros que em troca do recebimento de vantagens emprestam seu nome para serem utilizados nestes negócios escusos. (SANTOS, BERTONCINI, FILHO, 2015, p.171).

Ressalta-se que a hipótese não é limitada apenas à participação da pessoa física, também há a tipificação da conduta quando uma pessoa jurídica for utilizada para as finalidades previstas no dispositivo legal. 
Na situação descrita no inciso III do art. $5^{\circ}$ há um comportamento, o de ocultar ou dissimular, e duas finalidades, a primeira consistente na utilização de interposta pessoa física ou jurídica para ocultar ou dissimular interesses ilícitos, a segunda, caracterizada pela utilização de interposta pessoa física ou jurídica para ocultar ou dissimular a identidade dos beneficiários dos atos praticados. (SANTOS, BERTONCINI, FILHO, 2015, p.170).

Quando há a criação de uma pessoa jurídica com o objetivo de realizar as condutas tipificadas no inciso III do art. $5^{\circ}$, nota-se a atração da sanção prevista no inciso II do $\S 1^{\circ}$ do art. 19 (dissolução compulsória), uma vez que não há neste ato uma finalidade lícita, justa e socialmente adequada, mas sim a instrumentalização do ente jurídico para ocultar os verdadeiros responsáveis por práticas ilícitas e os beneficiários de seu aproveitamento econômico.

Neste caso, é comum que a vantagem obtida seja caracterizada como crime de lavagem de dinheiro, tipificado na conduta relativa à "ocultação ou dissimulação da natureza, origem, localização, disposição, movimentação ou propriedade de bens, direitos ou valores provenientes direta ou indiretamente, de infração penal" (art. $1^{\circ}$ da Lei 9.613).

Também possui correlação com o inciso II do $\S 1^{\text {o }}$ do art. 19 a hipótese prevista na alínea "e" do inciso IV do art. 5, que prevê como ato lesivo à administração pública a criação de modo fraudulento ou irregular de pessoa jurídica para participar de licitação ou celebrar contrato administrativo, o que também atrai a sanção prevista no inciso II do $§ 1^{\circ}$ do art. 19.

Deste modo, tanto no caso do inciso III quanto na hipótese da alínea "e" do inciso IV ambos do art. $5^{\circ}$, verifica-se que a criação da pessoa jurídica somente é justificada para o atendimento da prática de atos ilícitos, de modo que não será gerado nenhum benefício à sociedade, pelo contrário, somente produzirá mazelas indesejáveis aptas à prejudicar o erário, o que induz concluir que a função social da empresa jamais será respeitada ou, ao menos, jamais será almejada, de modo que não há justificativa para a preservação de uma empresa enquadrada nestas circunstâncias.

Portanto, na hipótese do inciso II do $\$ 1^{\circ}$ da Lei 12.846/2013 não há nenhuma incompatibilidade da pena de dissolução da pessoa jurídica com o princípio da preservação da empresa, pois jamais o ente criado cumpriria ou almejaria cumprir com uma função social. 


\subsection{Dissolução da pessoa jurídica pela utilização de sua personalidade jurídica de forma habitual para facilitar ou promover a prática de atos ilícitos}

O inciso I do $\S 1^{\circ}$ do art. 19 prevê a dissolução do ente jurídico quando a sua personalidade jurídica tiver sido utilizada de forma habitual para facilitar ou promover a prática de atos ilícitos.

Havendo a comprovação da utilização da personalidade jurídica para a prática de atos ilícitos de forma habitual, certamente estará tipificada a conduta prevista no inciso I do $\S 1^{\circ}$ do art. 19.

Apressadamente poder-se-ia concluir que o enquadramento da conduta no tipo legal justificaria a extinção da pessoa jurídica. Porém, em virtude da gravidade da sanção a questão demanda maior profundidade.

É certo que uma empresa que habitualmente está envolvida com a prática de atos ilícitos não observa integralmente a sua função social, ainda que gere empregos, tributos, produtos e serviços ao mercado, a sua atividade está deslocada da licitude e higidez que o ordenamento jurídico exige.

Há muito tempo a empresa não se resume à função meramente econômica, no sentido de produzir produtos ou prestar serviços visando única e exclusivamente ao lucro. Atualmente, pela necessidade Estatal de direcionar a atividade empresarial para que não haja prejuízo social, ou que os interesses sociais sejam relegados a segundo plano, viu-se na função social a possibilidade de se definir valores pelos quais os empresários devem se guiar ao desenvolver as suas atividades.

O que se vê na empresa, ao cumprir sua função social, é uma instituição responsável por realizar uma transformação social, além de possuir direitos e deveres perante a sociedade.

A dissolução da empresa em decorrência da utilização habitual de sua personalidade jurídica para a prática de atos ilícitos implica também na extinção de postos de trabalho, de fonte de receita de tributos e do nascimento de uma lacuna no mercado, o que pode afetar fornecedores e consumidores.

No tocante ao trabalho, a extinção da empresa poderia ser considerada uma ofensa ao princípio de seu valor social, pois a "valorização do trabalho humano e reconhecimento do valor social do trabalho consubstanciam cláusulas principiológicas que, ao par de afirmarem a 
compatibilização [...] portam em si evidentes potencialidades transformadoras". (GRAU, 2006, p. 199).

É pelo trabalho que se consegue obter dignidade, que se consegue obter o mínimo existencial, motivo pelo qual possui extrema relevância social, além de que a ordem econômica é "embasada em direitos sociais como o direito ao trabalho e à livre iniciativa" (NETO, 2013, p. 119), o que demonstra a importância de se buscar a preservação das condições de manutenção a estes direitos.

Diante das várias circunstâncias negativas, a preservação da empresa "atenderia, assim, ao interesse coletivo na medida em que essa unidade organizada de produção é fonte geradora de empregos, tributos e da produção ou mediação de bens e serviços para o mercado, sendo, assim, propulsora de desenvolvimento" (PEREZ, 2008, p. 206).

Porém, analisando as hipóteses previstas na Lei 12.846/2013, pode-se concluir que “andou bem o legislador em prever a possibilidade de dissolução e extermínio da pessoa jurídica que se afastou da finalidade social e passou a ser instrumento da criminalidade e também daquela pessoa jurídica que desde o início fora criada como arquitetura de fraudes e da criminalidade" (SANTOS, 2015).

Milita contra a preservação da empresa o fato de no decorrer de sua história ter passado de modo habitual "a servir de instrumento para a criminalidade e fraudes contra a Administração Pública" (SANTOS, 2015), mesmo que no momento de sua criação tivesse visado e almejado o desenvolvimento de atividade dentro da licitude e da higidez.

Também estaria justificada a aplicação da pena capital em decorrência das teorias preventivas da pena, cujo objetivo da sanção é prevenir a prática de novos ilícitos idênticos:

\footnotetext{
As teorias preventivas atribuem à pena a capacidade e a missão de evitar que no futuro se cometam novas infrações. É dizer, embora se reconheça que, segundo sua essência, a pena se traduz num mal para quem sofre, a sua função mais nobre consiste na prevenção geral, de incutir temor nos demais atores sociais para que não pratiquem atos ilícitos e incorram na mesma aflição (QUEIROZ, 2017, p. 617).
}

Porém, em virtude de todas as consequências que envolvem a questão, não é possível que se crave a resposta no sentido de que a empresa que utilizar a sua personalidade jurídica com habitualidade para a prática de atos ilícitos deve ser dissolvida, o que se propõe é que seja analisado caso a caso, e que a sanção da extinção seja aplicada somente como ultima ratio, priorizando as sanções relativas a (i) perdimentos dos bens, direitos ou valores que representem vantagem ou proveito obtidos com a infração, (ii) suspensão ou interdição parcial de suas 
atividades e (iii) proibição de receber incentivos, subsídios, subvenções, doações ou empréstimos de órgãos ou entidades públicas e de instituições financeiras públicas ou controladas pelo poder público, pelo prazo mínimo de 1 ano e máximo de 5 anos.

Após esgotadas as sanções citadas, em caso de não correção da pessoa jurídica à conformidade de suas atividades com a licitude, estará autorizada a pena de dissolução compulsória sem que este fato acarrete qualquer colisão com o princípio da preservação da empresa, pois neste caso estará caracterizada a impossibilidade de saneamento do vício, e consequentemente com a impossibilidade de atendimento integral à função social da empresa, uma vez que as suas atividades continuarão voltadas à prática de atos ilícitos.

\subsection{Dissolução da pessoa jurídica pela sua utilização na prática de atos ilícitos}

Por fim, a última hipótese a ser analisada diz respeito à dissolução da pessoa jurídica em virtude de sua utilização na prática de atos ilícitos.

Inicialmente, conforme exposto no tópico anterior, deve ser observada a existência de tipicidade da conduta, nesse sentido, como a Lei 12.846/2013 somente prevê a possibilidade de dissolução compulsória da pessoa jurídica nos casos em que (i) a personalidade jurídica tiver sido utilizada de forma habitual para facilitar ou promover a prática de ilícitos ou que (ii) a pessoa jurídica tiver sido constituída para ocultar ou dissimular interesses ilícitos ou a identidade dos beneficiários dos atos praticados.

Desde que a pessoa não tenha sido criada com o objetivo previsto no inciso II do $\S 1^{\circ}$ do art. 19, a conduta não será típica, do mesmo modo se a prática de atos ilícitos não ocorrer de forma habitual, isso porque deve vigorar o princípio da tipicidade fechada.

Desta forma, nos casos em que se verificar a prática de atos lesivos à administração pública previstos nos incisos do art. $5^{\circ}$ da Lei 12.846/2013, as sanções aplicáveis devem correspondem aos incisos I, II e IV do art. 19.

Portanto, a pessoa jurídica que comete as condutas descritas no art. $5^{\circ}$ da Lei 12.846/2013 sem habitualidade, somente pode ser sancionada com (i) perdimentos dos bens, direitos ou valores que representem vantagem ou proveito obtidos com a infração, (ii) suspensão ou interdição parcial de suas atividades e (iii) proibição de receber incentivos, subsídios, subvenções, doações ou empréstimos de órgãos ou entidades públicas e de instituições 
financeiras públicas ou controladas pelo poder público, pelo prazo mínimo de 1 ano e máximo de 5 anos.

A dissolução compulsória nesta situação seria considerada um abuso do poder punitivo estatal, ainda que a empresa tenha desviado da licitude, há a possibilidade de correção, de modo a retornar a cumprir com sua função social integralmente.

Nesta situação não se verifica colisão entre a dissolução e o princípio da preservação da empresa ou de sua função social, uma vez que não se pode cogitar da aplicação da pena capital à pessoa jurídica por ausência de tipicidade.

\section{CONSIDERAÇÕES FINAIS}

Conforme verificado, a Lei Anticorrupção (Lei 12.846/2013) apesar de louvável a sua tentativa de combater os atos de corrupção empresarial criou uma aparente situação de conflito entre a previsão de dissolução compulsória da pessoa jurídica e os princípios da função social da empresa e de sua preservação.

Como forma de verificar a existência ou não de conflito a pesquisa analisou três hipóteses distintas: (i) a pessoa jurídica constituída para ocultar ou dissimular interesses ilícitos ou a identidade dos beneficiários dos atos praticados (inciso II do $\S 1^{\circ}$ do art. 19), (ii) a pessoa jurídica que utiliza habitualmente a sua personalidade jurídica para facilitar ou promover a prática de atos ilícitos (inciso I do $\S 1^{\circ}$ do art. 19) e, por fim, (iii) a pessoa jurídica utilizada para a prática de atos ilícitos.

Quanto à primeira hipótese, verificou-se não haver conflito algum entre a sanção prevista na Lei 12.846/2013 e os princípios da função social e da preservação da empresa, isso porque a pessoa jurídica nesse caso é criada com o único e exclusivo fim de ocultação ou dissimulação de interesses ilícitos ou dos beneficiários dos atos praticados; desse modo, a sua existência em nada contribui para o desenvolvimento nacional e para a promoção social, de maneira que não se cogita ter esse tipo de empresa qualquer função social que justifique a sua preservação.

A mesma conclusão não se obteve no tocante à segunda hipótese analisada, isso porque apesar de entender haver tipicidade na conduta praticada, os efeitos da extinção da empresa podem acarretar enormes prejuízos sociais, principalmente quanto à extinção de postos de 
trabalho e de fonte de arrecadação de tributos para o Estado, além de uma lacuna no mercado, que poderia afetar fornecedores e consumidores.

Diante dessa situação socialmente gravosa, conclui-se pela necessidade de ponderação quanto à aplicação das sanções à pessoa jurídica, motivo pelo qual entende-se mais adequado que sejam pespegadas primeiramente as sanções de (i) perdimentos dos bens, direitos ou valores que representem vantagem ou proveito obtidos com a infração, (ii) suspensão ou interdição parcial de suas atividades e (iii) proibição de receber incentivos, subsídios, subvenções, doações ou empréstimos de órgãos ou entidades públicas e de instituições financeiras públicas ou controladas pelo poder público, pelo prazo mínimo de 1 ano e máximo de 5 anos.

Após a aplicação das referidas sanções - sem prejuízo da punição das pessoas físicas envolvidas -, e em se constatando a continuidade na prática de atos lesivos pela pessoa jurídica, estaria autorizada, como última ratio, a aplicação da sanção de dissolução compulsória, uma vez que houve a oportunidade de correção do comportamento ilícito, sem, no entanto, que tenha surtido efeitos, motivo pelo qual não se pode permitir a manutenção na sociedade de instituição que não é capaz de gerar benefícios à comunidade e, consequentemente, não cumprindo com sua função social, o que permite o afastamento do princípio da preservação da empresa. Em outros termos, na segunda hipótese da pesquisa, a dissolução compulsória seria medida excepcional, empregada subsidiariamente após demonstrada a ineficácia das demais sanções da Lei Anticorrupção aplicadas em casos pretéritos.

Por fim, da análise da última hipótese, concluiu-se pela impossibilidade de aplicação da sanção de dissolução compulsória da pessoa jurídica ante a ausência de tipicidade; porém, nada impedindo o sancionamento da empresa com base nos incisos I, II e IV do art. 19 da Lei 12.846/2013. Assim, neste caso, não se vislumbra a existência de conflito entre a possibilidade de extinção e os princípios da função social e da preservação da empresa.

Em síntese, o Direito Administrativo Sancionador, representado pela Lei 12.846/2013, deve ser aplicado de modo a se combater os atos de corrupção e, ao mesmo tempo, não olvidar do respeito ao princípio constitucional da função social da empresa e ao princípio da preservação da pessoa jurídica, de maneira que a dissolução da empresa privada empregada na prática de atos lesivos à Administração Pública seja medida aplicada de forma estrita e excepcional, como demonstrado neste artigo. 


\section{REFERÊNCIAS}

SANTOS, José Anacleto Abduch. BERTONCINI, Mateus. FILHO, Ubirajara Custódio. Comentários à Lei 12.846/2013: Lei anticorrupção, 2. ed. rev. atual. e ampl. São Paulo, Editora Revista dos Tribunais, 2015.

ADAMS, Fernanda. OLIVEIRA, Marcella Gomes. Responsabilidade social e função social da empresa. In: Ética, ciência e cultura jurídica: IV Congresso Nacional da FEPODI: [Recurso eletrônico on-line] organização FEPODI/CONPEDI/ANPG/PUC-SP/UNINOVE; coordenadores: Livia Gaigher Bosio Campello, Mariana Ribeiro Santiago - São Paulo: FEPODI, 2015.2 Disponível em <https://www.conpedi.org.br/publicacoes/z3071234/gei62151/8hYF25asipu16YE7.pdf> Acesso em 25.fev.2018.

BRASIL, Constituição da República Federativa do Brasil de 1988. Disponível em: < http://www.planalto.gov.br/ccivil_03/Constituicao/Constituicao.htm>. Acesso em 5. ago.2018.

BRASIL, Lei no 9.613, de 13 de março de 1998. (Lei de "lavagem de dinheiro") Disponível em: < http://www.planalto.gov.br/CCIVIL_03/leis/L9613.htm>. Acesso em 5. ago.2018.

BRASIL, Lei $\mathrm{n}^{\circ}$ 10.406, de 10 de janeiro de 2002. (Código Civil) Disponível em: < http://www.planalto.gov.br/ccivil_03/leis/2002/110406.htm >. Acesso em 5. ago.2018.

BRASIL, Lei $n^{\circ} 12.846$, de $1^{\circ}$ de agosto de 2013. (Lei Anticorrupção) Disponível em: <http://www.planalto.gov.br/ccivil_03/_ato2011-2014/2013/lei/112846.htm>. Acesso em 5. ago.2018.

DWORKIN, Ronald. Taking Rights Seriously. Cambridge, Mass.: Harvard University Press, 1977.

ETCHEVERRY, Raúl Aníbal. Derecho comercial y económico: parte general. 1. reimp. Buenos Aires: Astrea, 1994.

FILHO, André Pimentel. Comentários aos artigos $1^{\circ}$ ao $4^{\circ}$ da Lei Anticorrupção. In: Lei Anticorrupção e temas de compliance, Organizadores Jorge Munhós de Souza e Ronaldo Pinheiro de Queiroz 2 ed. rev., ampl. e atual. Salvador: Editora Juspodivm, 2017.

GARCIA-MARZÁ, Domingo. Ética Empresarial: do diálogo à confiança na Empresa. São Leopoldo; Pelotas/RS: Editora Unisinos, Educat, 2007.

GRAU, Eros Roberto. A Ordem Econômica na Constituição de 1988. 8 ed. São Paulo: Malheiros, 2006.

MAMEDE, Gladston. Direito Empresarial Brasileiro: empresa e atuação empresarial. 7. ed. São Paulo: Atlas, 2013.

NETO, Carlos Martins. Preservação da empresa e ativismo judicial. In: Revista Semanal de Direito Empresarial, Rio de Janeiro, $\mathrm{n}^{\mathrm{o}}$ 13, jul-nov. 2013. Disponível em: <https://www.academia.edu/31561672/PRESERVA\%C3\%87\%C3\%83O_DA_EMPRESA_E _ATIVISMO_JUDICIAL_BREVES_NOTAS_SOBRE_A_EXPERI\%C3\%8ANCIA_BRASI LEIRA> Acesso em: 1.mar.2018. 
PEREZ, Viviane. Função social da empresa: uma proposta de sistematização do conceito. In: Temas de direito civil-empresarial. Rio de Janeiro: Renovar, 2008. p. 206.

QUEIROZ, Ronaldo Pinheiro. Responsabilização judicial da pessoa jurídica na lei anticorrupção. In: Lei Anticorrupção e temas de compliance, Organizadores Jorge Munhós de Souza e Ronaldo Pinheiro de Queiroz 2 ed. rev., ampl. e atual. Salvador: Editora Juspodivm, 2017.

RICCI, Henrique Cavalheiro. Função social da empresa é valor e não norma jurídica. Disponível em: https://www.conjur.com.br/2012-out-25/henrique-ricci-funcao-socialempresa-valor-nao-norma-juridica. Acesso em 24.fev.2018.

SANTIAGO, Mariana Ribeiro. Princípio da Função Social do Contrato. 2 ed. Curitiba: Juruá, 2008.

SANTOS, Kleber Bispo. Das sanções da lei anticorrupção à luz da ponderação de interesses, 2015. Disponível em: https://esaoabsp.edu.br/Artigo?Art=141 . Acesso em 26.fev.2018.

TOMASCEVICIUS FILHO, Eduardo. A Função social da empresa. Revista dos Tribunais, São Paulo, n. 92, p. 33-50, abr. 2003.

TOMAZETTE, Marlon. Curso de Direito Empresarial: falências e recuperação de empresas. Vol. 3. Atlas: São Paulo, 2011. 